\title{
Assessment of documentation on current patient's medical records at Accident and Emergency Hospital of Sulaimani-Iraq
}

\author{
Delan Jamal Qader \\ Department of Adult Nursing \\ College of Nursing \\ University of Sulaimani \\ Sulaymaniyah, Iraq \\ delan.qader@univsul.edu.iq
}

\author{
Faruk Hasan Faraj \\ Department of Surgery \\ College of Medicine \\ University of Sulaimani \\ Sulaymaniyah, Iraq \\ faruk.faraj@univsul.edu.iq
}

Volume 4 - Issue 2

December 2019

DOI:

10.24017/science.2019.2.2

Received:

17 August 2019

Accepted:

10 September 2019

\begin{abstract}
The patient record is an essential patient data were the nursing documentation part is fundamental. .Competent nursing care is based on correct and complete records, and keeping record is an essential skill that needs to be developed by each and every health staff. The present study was conducted in order to assess the documentation on current medical patient's records in the Accident and Emergency Hospital/Sulaimani city. A quantitative descriptive design. Research was accomplished, based on retrospective data made available by the Accident and Emergency Hospital. Non-probability (purposive sample) of 201 patient files were selected from 1,194 patient files during 6 months between Jun to December 2016.The present study showed that the face sheet was completely recorded about \%95 which means satisfactory, other items which were recorded by physician such as chief complaint and history of present illness, radiology, laboratory, medication intervention report, consent forms, physical examination, and consultant report were unsatisfactorily recorded. Last items which were recorded by the nurse who working in Accident and Emergency Hospital medication and administration record and a graphic sheet of vital signs were unsatisfactorily recorded. Deficiency in documentation system and most of the provided medical and nursing care remains undocumented given numerous deficiencies in the documentation system. It is recommended the components of the nursing record tool can be utilized once a paperless system is implemented as planned in the hospital.
\end{abstract}


Keywords: Assessment, Documentation, Medical record, Accident and Emergency Hospital, Current medical records.

\section{INTRODUCTION}

According to the work of Werley and Lang1985, the three important categories for the nursing record are demographic, services and nursing care [1].The Sweden well-being, integrity, prevention and security (VIPS) model by Ehnfors et.al in 1991 and it has been updated in 2015[2], proposed a structured nursing record in an easily and adequate method (Fig. 1). The purpose of the model is to guide the nurse in the sequences of assessment, problem identification, aim, planning of interventions, implementation and evaluation of results and thereby to make nursing documentation structured, adequate and easy to use in clinical care [3, 4]. In the VIPS model, 14 keywords are used for classifying patient related information collected by the Nurses into categories e.g., communication, nutrition and psychosocial status. Ten keywords classify nursing interventions into categories such as information, support and environment.

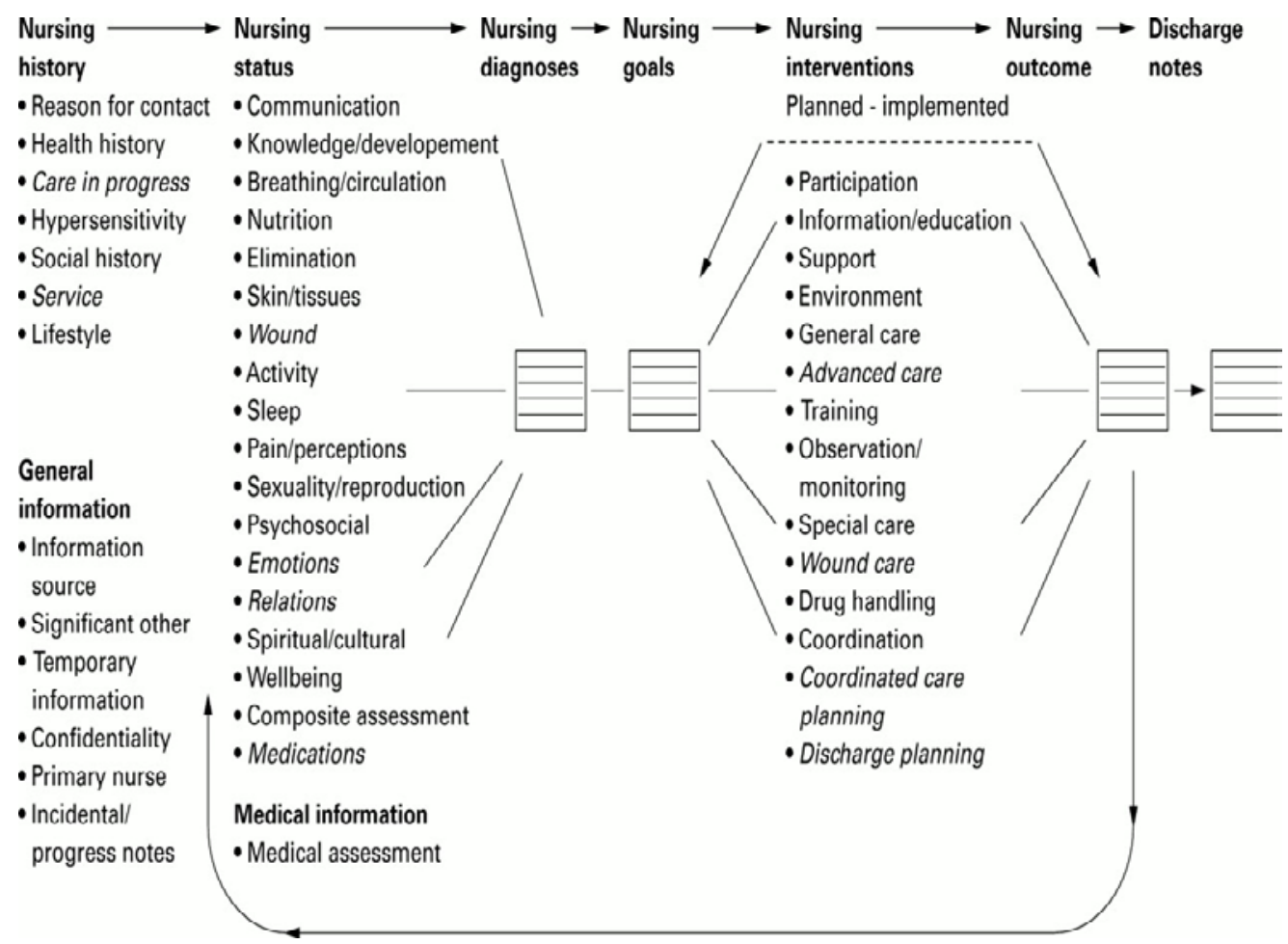

Figure 1:Illustration of the VIPS model for nursing documentation [4]

Medical Audit is defined as the process were the medical staff collectively review assess and evaluate the structure, process, and outcome[5].The medical record is an actual effectual image of medical care hence it is the mere image of the quality of the nursing performance [6]. As a retrospective type of auditing where the medical record is evaluated after the discharge of the patient[6, 7].

Nursing record assessment or evaluation revealed that there are differences in nursing documentation among nurses in several aspects of medical records. Auditing of this record and their conclusion and recommendation improves better quality and achievement [8- 
11].Besides that, documenting the nursing note contributes to evaluating patient's goals attainment as a result of nursing care, determining care, which is provided by the current progress toward the expected outcome, communication among caregiver opportunity, for reimbursement purposes, legal protection and enhancing nursing knowledge [12] . To the best of our knowledge, no previous study was conducted in Sulaimani province. For this purpose, this study aimed to assess of documentation on current patient's medical records at Accident and Emergency Hospital of Sulaimani in Kurdistan Region of Iraq.

\section{METHODS AND MATERIALS}

\subsection{Study design and setting}

A quantitative descriptive research was accomplished, based on retrospective data available by the Accident and Emergency Hospital. This hospital was built in 2005. Accident and Emergency hospital is one of the vital areas of the Sulaimani city/Iraq for the injured patient that deals with critical cases and care which is highly in need for qualified and well-trained nurses to manage, diagnosis problem and intervene their works effectively, particularly during emergency situation. An audit instrument in use at the Accident and Emergency Hospital was adapted by ensuring that it was specific to the study objectives. A form is useful for auditing the actual nursing record and care in this hospital.

\subsection{Study sample}

Non-probability (purposive sample) of 201 patient files were selected from 1,194 patient files during 6 months between Jun to December 2016. Patient care was evaluated by auditing the patient chart records who were hospitalized in Accident and Emergency Hospital Sulaimani /Iraq.

\subsection{Study Instruments}

For the purpose of the present study, the researcher constructs the study instrument to evaluate patient's files in the Accident and Emergency Hospital: It was based on extensive review of related literature and studies. The study instruments consist of twelve parts which include total of (53) items, which are distributed according the following: (face sheet, consultant report, medical history and history of present illness, laboratory report, radiology report, medication administration record, flow sheet, discharge and summery not, graphic sheet and consultant form). The Nursing Care Quality Control Advisory Council Measurement (NCQCAC) [10] has been used to assess the level of satisfaction of the Auditing patient's chart of each patient's file. The NCQCAC measurement classified the patient's chart according to the extent to which information has been recorded (Table 1).

Table 1: Satisfaction levels according to criteria used in quality assessment by the (NCQCAC) of a university hospital [13]

\begin{tabular}{llllc}
\hline Satisfaction level & \multicolumn{4}{c}{ Assessment criteria } \\
\cline { 2 - 5 } & Complete & Incomplete & Not Completed & Incorrect \\
\hline Satisfactory & Above $80 \%$ & Below 15\% & Below5\% & $0 \%$ \\
\hline Unsatisfactory & Below $80 \%$ & Above $15 \%$ & Above $5 \%$ & Above $0 \%$ \\
\hline
\end{tabular}

\subsection{Data collection}

The researcher entered the patient file information to SPSS Data Sheet. All data regarding patient information, (Face sheet (Demographic data), Consultant report, Medical history, Laboratory report, Radiology report, Medication administration record, intervention, Flowsheet of physical examination, Discharge and summary note, Graphic sheet and Consent Formwas include the study.

\subsection{Data analysis}

The data were analyzed with the Statistical Package for the Social Sciences (SPSS) version (22.0) were used in order to achieve the objectives of the study. Information related to each section of the patient file records was present distinctively in the following tables. 


\subsection{Ethical considerations}

As soon as approval was issued for the objective of the study, official permission was obtained from the College of Medicine, Sulaimani-Iraq. Another approach was issued from the Health Directorate of Sulaimani. Also, official permission was retrieved from the Emergency and Accidental Hospital administration .It is a condition of registration to abide by Accident and Emergency Hospital guidance, which include requirements to respect patient confidentiality by omitting patient name.

\section{RESULTS}

The overall demographic data record was at satisfactory level according to (NCQCAC). In this section, Medical diagnosis item was the lowest recorded data in the patient chart which was $72.1 \%$ (Table 2 ).

Table 2: Documented Face sheet information

\begin{tabular}{llcccc}
\hline 1. Face sheet (Demographic data) & \multicolumn{2}{c}{ Complete record } & \multicolumn{2}{c}{ No record } \\
\cline { 2 - 5 } & $\mathbf{F}$ & $\mathbf{\%}$ & $\mathbf{F}$ & $\mathbf{\%}$ \\
\hline Name & 201 & 100 & 0 & 0 \\
\hline Age & 201 & 100 & 0 & 0 \\
\hline Sex & 200 & 99.5 & 1 & 0.5 \\
\hline Occupation & 200 & 99.5 & 1 & 0.5 \\
\hline Place & 200 & 99.5 & 1 & 0.5 \\
\hline Tel NO. & 200 & 99.5 & 1 & 0.5 \\
\hline Admission Unit & 185 & 92 & 16 & 8 \\
\hline Dr. responsible & 185 & 92 & 16 & 8 \\
\hline Medical Diagnosis & 145 & 72.1 & 56 & 27.9 \\
\hline Overall & 1717 & 95 & 92 & 5 \\
\hline
\end{tabular}

The overall data of the chief complaint and history of present illness was recorded to not satisfactory level. Social history, Family history, and surgical history were the main low recorded items by $48.8 \%, 42.3 \%$ and $38.2 \%$ respectively (Table 3 ). Regarding to (Table 4 ) each items was unsatisfactorily recorded.

Table 3: Chief complaint and medical history Part

\begin{tabular}{llcccc}
\hline 2. Chief complaint and history present illness & Complete record & \multicolumn{2}{c}{ No record } \\
\cline { 2 - 5 } & $\mathbf{F}$ & $\mathbf{\%}$ & $\mathbf{F}$ & $\mathbf{\%}$ \\
\hline Chief complaint & 170 & 84.6 & 31 & 15.4 \\
\hline Duration & 129 & 64.2 & 72 & 35.8 \\
\hline Social history (tobacco ,alcohol ,drugs) & 98 & 48.8 & 103 & 51.2 \\
\hline Family history & 85 & 42.3 & 116 & 57.7 \\
\hline Surgical history & 117 & 58.2 & 84 & 41.8 \\
\hline Medical history & 121 & 60.2 & 80 & 39.8 \\
\hline Overall & 550 & 54.7 & 455 & 45.3 \\
\hline
\end{tabular}

Table 4: Distribution of filling laboratory, radiology report, and medication intervention and consent form record parts.

\begin{tabular}{llccccc}
\hline \multirow{2}{*}{ Items } & \multicolumn{2}{c}{ Complete record } & \multicolumn{3}{c}{ No record } \\
\cline { 2 - 6 } & Laboratory report & $\mathrm{F}$ & $\%$ & $\mathrm{~F}$ & $\%$ \\
\hline 3. & Radiology reportX-Ray & 19 & 0 & 201 & 100.0 \\
\hline
\end{tabular}




\begin{tabular}{llcccc}
\cline { 2 - 5 } & $\begin{array}{l}\text { Medication intervention } \\
\text { record }\end{array}$ & 0 & 0 & 201 & 100.0 \\
\hline 4. & Consent forms & 34 & 16.9 & 167 & 83.1 \\
\hline
\end{tabular}

The overall physical assessment documentation's level was unsatisfactorily recorded. In all items, Airway 57.7\%, Breathing 51.7\% and consciousness 56.7\% were completely recorded (Table 5).

Table 5: Distribution of flow sheet on Physical assessment documentation

\begin{tabular}{lcccccc}
\hline \multirow{2}{*}{ 5. Physical assessment } & \multicolumn{2}{c}{ Complete Record } & Incomplete Record & \multicolumn{2}{c}{ No record } \\
\cline { 2 - 7 } & $\mathrm{F}$ & $\%$ & $\mathrm{~F}$ & $\%$ & $\mathrm{~F}$ & $\%$ \\
\hline Airway & 116 & 57.7 & 0 & 0 & 85 & 42.3 \\
\hline Breathing & 104 & 51.7 & 0 & 0 & 97 & 48.3 \\
\hline cardiovascular & 11 & 5.5 & 7 & 3.5 & 183 & 91.0 \\
\hline Consciousness & 114 & 56.7 & 0 & 0 & 87 & 43.3 \\
\hline skin & 92 & 45.8 & 1 & 0.5 & 108 & 53.7 \\
\hline Gastrointestinal & 31 & 15.4 & 21 & 10.4 & 149 & 74.1 \\
\hline Injury & 27 & 13.4 & 9 & 4.5 & 165 & 82.1 \\
\hline Burns & 11 & 5.5 & 1 & 0.5 & 189 & 94.0 \\
\hline Musculoskeletal & 10 & 5.0 & 5 & 2.5 & 186 & 92.5 \\
\hline Wound description & 7 & 3.5 & 1 & 0.5 & 193 & 96.0 \\
\hline Neurology & 9 & 4.5 & 15 & 7.5 & 177 & 88.1 \\
\hline \multicolumn{1}{c}{ Overall } & 532 & 24 & 60 & 2 & 1639 & 74 \\
\cline { 2 - 7 } & & & Unsatisfactory & & \\
\hline
\end{tabular}

The overall Medication administration record (MAR) was unsatisfactorily recorded. The main items of MAR including route (86.1\%), date (40.3\%) and time (39.8\%) of drugs were no recorded (Table 6).

Table 6: Distribution of filling medication admiration sheet

\begin{tabular}{|c|c|c|c|c|}
\hline \multirow[b]{2}{*}{$\begin{array}{c}\text { Medication administration record } \\
\text { (MAR) }\end{array}$} & \multicolumn{2}{|c|}{ Complete Record } & \multicolumn{2}{|c|}{ No Record } \\
\hline & $\mathbf{F}$ & $\%$ & $\mathbf{F}$ & $\%$ \\
\hline Name of drugs & 201 & 100 & 0 & 0 \\
\hline Route & 27 & 13.4 & 173 & 86.1 \\
\hline Dose & 155 & 77.1 & 46 & 22.9 \\
\hline Date & 120 & 59.7 & 81 & 40.3 \\
\hline Time & 121 & 60.2 & 80 & 39.8 \\
\hline Signature (nurses) & 175 & 87.1 & 26 & 12.9 \\
\hline \multirow[t]{2}{*}{ Overall } & 799 & 66.4 & 406 & 33.6 \\
\hline & \multicolumn{4}{|c|}{ Unsatisfactory } \\
\hline
\end{tabular}

The overall graphic sheet of vital signs was not recorded satisfactorily. In Graphic sheet ,it was showed that three-quarter of items no recorded by date $79.6 \%$,time $77.1 \%$, respiration rate $77.1 \%$, saturation $75.1 \%$, O2 flow rate78.6\%,blood pressure $78.1 \%$,heart rate $77.6 \%$,body temperature78.1\%,and GCS $81.1 \%$,also just $4 \%$ of sample recorded pain scales and total sample not recorded nursing note (Table 7). 
Table7: Distribution of filling graphic sheet of vital signs

\begin{tabular}{lcccc}
\hline \multirow{2}{*}{ 7. The graphic sheet of vital signs } & \multicolumn{2}{c}{ Complete Record } & \multicolumn{2}{c}{ No record } \\
\cline { 2 - 5 } & F & \% & F & \% \\
\hline Date & 41 & 20.4 & 160 & 79.6 \\
\hline Time & 46 & 22.9 & 155 & 77.1 \\
\hline Respiration Rate & 46 & 22.9 & 155 & 77.1 \\
\hline Saturation & 50 & 24.9 & 151 & 75.1 \\
\hline O2 flow rate & 43 & 21.4 & 158 & 78.6 \\
\hline Blood pressure & 44 & 21.9 & 157 & 78.1 \\
\hline Heart rate & 45 & 22.4 & 156 & 77.6 \\
\hline Body Temperature & 44 & 21.9 & 157 & 78.1 \\
\hline Conscious (GCS) & 38 & 18.9 & 163 & 81.1 \\
\hline Pain scale & 8 & 4.0 & 193 & 96.0 \\
\hline Nursing Note & 0 & 0 & 201 & 100.0 \\
\hline Overall & 405 & 18.3 & 1806 & 81.7 \\
\cline { 2 - 5 } & \multicolumn{4}{c}{ Unsatisfactory } \\
\hline
\end{tabular}

\section{DISCUSSION}

To assess current patient's medical records, this study has chosen patients file in accident and emergency hospital which prepared as a checklist according to items in retrospective patients file. This included a total of 201 patient's medical records allowed in different units of the Accident and Emergency Hospital. The complex task of nursing documentation was reported to be guided by an appropriate framework to tackle patients care issues, the nursing process, and a high quality nursing care [14].

Our study conducted to assess the satisfactory level of patient's medical records and the adherence of medical staff to document patient's information is accurate and proper manner, the data which, were used in this study can be verified for its completeness, but we believe that this study provides sufficient evidence about the quality of documentation in Accident Emergency Hospital which, could be generalized to other hospitals in the city. Our assumption in the current study was that any activity that not recorded or documented assumed to have not been done and neglected.

Regarding face sheet, it was completely recorded about \%95 by non-medical staff. This means the recorded data was satisfactory. Other items as shown in others Tables were recorded by the physician (chief complaint and history of present illness, radiology, laboratory, medication intervention report, consent forms, flow sheet(physical examination ), and consultant report were unsatisfactorily recorded.. Last items which were recorded by the nurse who works in Accident and Emergency Hospital (medication and administration record and a graphic sheet of vital signs) in Table (6) and (7) were unsatisfactorily. Our result is in consistent to the studies done by Coffin [15, 16]Which indicate incomplete nursing documentation in emergency hospital [17].

In contrast to the current study, in Jamaica study [18]stated that nursing records was perfect in the majority of record .they also declared quarter defect in nursing diagnosis. In Kufa-Iraq the study was done by Jebus and Mohammed[19] reported that the overall evaluation of vital signs documentation was moderate. These data disagreed with our results. Regarding nursing note documentation less accurate, it shows the same as this study found.

The current study, consistent with reports from other sub-Saharan African countries study which showed deficiency in the nursing record. It was shown that $46 \%$ of the inpatient nursing care in Eastern Ghana were unsatisfactorily recorded and notes about 63\% of patients after the first time of admission [20]. Therefore, it was not straight forward to compare with other similar studies from the Ethiopian context due to the lack of limited data of available literature. In this study, it was surprisingly observed that the nursing documentation practice was higher than that obtained in study from European hospitals where it was just 28\% [21]. 
In spite of, the present study in Basrah/Iraq, was done by Al-Bassam[22] about misconduct in medical records documentation of patients admitted to surgical department at Basrah general hospital, shows that the documentation varies from item to other, for information related to patient identity: name, address, occupation presented completely in 70\%, 19.2\%, and 60.9\% respectively. Regarding medical history, the chief complaint was written in medical term in $39.2 \%$ while the duration of illness was documented in $57.2 \%$, whereas present illness, review of system, past, social, family and drugs histories were completely presented in $17.6 \%, 1.6 \%$, $19.6 \%, 3.6 \%$, 2\%, 20.8\% respectively. Also, $38.8 \%$ for general examination, $66 \%$ for systemic examination, 32.4\% for vital signs, $94.8 \%$ for preoperative and operative anesthetic notes, and $46.8 \%$ for operative surgeon notes were not presented at all. The investigations \& treatment present in $71.6 \%$ and $56.8 \%$ respectively while the diagnosis was not mentioned in 87.4\%. Regarding follow up, nursing notes, consent was not present in approximately $30 \%$ of data. The admission sheet was not present in $2.8 \%$ while discharging summary report was not present in $97.2 \%$. For diet, height, weight, the fluid chart was not recorded at all, these data which completely agree with the result of this study..

Another study in South Africa was done [23] recorded that vital sign documentation, completion of recordings was $81 \%$ heart rate, $88 \%$ respiratory rate, $98 \%$ blood pressure, $92 \%$ temperature and $41 \%$ GCS. These data were completely disagreed with our result which were showed (22.9\% respiratory rate, $21.9 \%$ blood pressure, $22.4 \%$ heart rate, $21.9 \%$ body temperature, 18.9 GCS). In both studies, it might be due to an insufficient number of nurses/bed ratio or qualified nurses and inadequate financial income in Sulaimani city/Iraq. Documentation of vital signs can be improved the quality and safety of patient care, therefore we should develop a system for recording vital signs observations at the beside to yield an early warning score and saving data.

Another study was done in Jamaica, the study reported the results recorded for three hospitals. The results noted as follow: $81.6 \%$ for the patient's chief complaint, $78.8 \%$ for history of present illness, $79.2 \%$ for past health, and only $11.0 \%$ for family health. In addition, adequate assessment data were less than $1 / 3$ recorded by the audited. The audit also observed $90 \%$ of records which had a physical assessment were completed during twenty four hours of entries and admission timed, signed, and dated by a nurse. Patient teaching and discharge planning carried out within seventy two hours of admission were recorded to be $5 \%$ and $13.5 \%$ respectively. These findings disagreed with our result in the same items except in physical assessment is very low (24\%) and missing patient teaching. there is a strong evidence between patient mortality rate and quality of nursing documentation [24, 25].

Lack of interest about the significant of medical record bedsides deficiency of computerized system of medical record contributes to weak medical record [20] basically the nurses understands the importance of documentation but practically there is deficiency in achieving adequate nursing record [26].Improper documentation will confuse the subsequent medical care by nurses or medical staff subsequently failure leads to poor health care, outcome and increases patient dissatisfaction[27].Nurses are contextualized ,so there is a consensus that "nurses bear a large burden on both managing and implementing the interdisciplinary team's plan for the patient” [28]. Nurses may ignore complete nursing record to insure better nursing care for the patient, therefore nurses spend adequate time to perform their job deficiently rather than spending time on comprehensive medical record [29]

\section{CONCLUSION}

This retrospective study is to assess the documentations of patient records. It is conclude that the standard of nursing care documentation is under expectation; the documentation of patient medical records in Accident and Emergency hospital is unsatisfactory in general, as the majority of the patient records items were undocumented and below than the standard. 


\section{RECOMMENDATION}

The importance of patient identification should be emphasized and continuous professional development should focus on documentation. Clinical audits should be implemented and rigorous control of the correct procedures pertaining to patient identification should be executed. The components of the nursing record tool can be utilized once a paperless system is implemented as planned in the hospital.

\section{REFRENCES}

[1] H. H. Werley, and N. M. Lang, Identification of the nursing minimum data set: Churchill Livingstone, 1988.

[2] R. M. Olsen, "Informasjonsutveksling mellom sykepleiere i hjemmesykepleie og sykehus ved overføring av eldre pasienter,” Mittuniversitetet, 2013.

[3] M. Ehnfors, I. Thorell-Ekstrand, and A. Ehrenberg, “Towards basic nursing information in patient records,” Vård i Norden, vol. 11, no. 3-4, pp. 12-31, 1991.

[4] A. Ehrenberg, M. Ehnfors, and I. Thorell-Ekstrand, "Nursing documentation in patient records: experience of the use of the VIPS model,” Journal of Advanced Nursing, vol. 24, no. 4, pp. 853-867, 1996.

[5] I. Chiavenato, Administração de recursos humanos: fundamentos básicos: Atlas, 2003.

[6] P. Kurcgant, “Auditoria em enfermagem,” Revista Brasileira de Enfermagem, vol. 29, no. 3, pp. 106-124, 1976.

[7] D. A. d. Souza, and A. S. Fonseca, "Auditoria em enfermagem: visão das enfermeiras do município de São Paulo,” Nursing (São Paulo), vol. 8, no. 84, pp. 234-238, 2005.

[8] G. Brown, "Wound documentation: managing risk,” Advances in skin \& wound care, vol. 19, no. 3, pp. 155-165, 2006.

[9] P. Miller, and C. Pastorino, "Daily Nursing Documentation Can Be Quick and Thorough!!,” Nursing management, vol. 21, no. 11, pp. 47-49, 1990.

[10] Y. Porter, "Brief: Evaluation of nursing documentation of patient teaching," The Journal of Continuing Education in Nursing, vol. 21, no. 3, pp. 134-137, 1990.

[11] R. A. Tapp, “Inhibitors and facilitators to documentation of nursing practice," Western journal of nursing research, vol. 12, no. 2, pp. 229-240, 1990.

[12] B. Kozier, G. Erb, and A. and Berman, Fundamental of nursing, concepts, process and practice, 7th. Edition ed., p.^pp. pp: 245-350., U.S.A. , 2004.

[13] F. G. Borsato, M. Â. Rossaneis, M. d. C. F. L. Haddad, M. T. O. Vannuchi, and D. W. Vituri, “Assessment of quality of nursing documentation in a University Hospital,” Acta Paulista de Enfermagem, vol. 24, no. 4, pp. 527-533, 2011.

[14] B. Yildirim, and S. Ozkahraman, “Critical thinking in nursing process and education,” International journal of humanities and social science, vol. 1, no. 13, pp. 257-262, 2011.

[15] E. G. C. Silva, V. C. d. Oliveira, G. B. C. Neves, and T. M. R. Guimarães, "Nurses' knowledge about Nursing Care Systematization: from theory to practice,” Revista da Escola de Enfermagem da USP, vol. 45, no. 6, pp. 1380-1386, 2011.

[16] V. G. Setz, and M. D'Innocenzo, "Evaluation of the quality of nursing documentation though the review of patient medical records,” Acta Paulista de Enfermagem, vol. 22, no. 3, pp. 313-317, 2009.

[17] M. D'Innocenzo, and N. P. Adami, "Análise da qualidade dos registros de enfermagem nos prontuários de pacientes de hospitais de ensino e universitários,” Acta paul. enferm, vol. 17, no. 4, pp. 383-391, 2004.

[18] C. Blake-Mowatt, J. Lindo, and J. Bennett, "Evaluation of registered nurses' knowledge and practice of documentation at a J amaican hospital,” International nursing review, vol. 60, no. 3, pp. 328-334, 2013.

[19] H. G. Jebur, and W. Mohammed, "Evaluation of Nursing Staffs' Documentation Standard Related to Nursing Procedures at Medical Wards in Al-Najaf Al-Ashraf Governorate,” Kufa Journal for Nursing Sciences| مجلة|لكوفةللعلومالتمريضية, vol. 6, no. 3, 2017.

[20] J. A. Asamani, F. D. Amenorpe, F. Babanawo, and A. M. A. Ofei, "Nursing documentation of inpatient care in eastern Ghana,” British Journal of Nursing, vol. 23, no. 1, pp. 48-54, 2014.

[21] J. E. Ball, P. Griffiths, A. M. Rafferty, R. Lindqvist, T. Murrells, and C. Tishelman, “A cross-sectional study of 'care left undone'on nursing shifts in hospitals,” Journal of Advanced Nursing, vol. 72, no. 9, pp. 2086-2097, 2016.

[22] S. M. Al-Bassam, "Misconduct In Medical Records Documentation Of Patients Admitted To Surgical Department At Basrah General Hospital. A Cross Sectional Study Of 250 Medical Records,” Basrah Journal of Surgery, vol. 22, no. 1, pp. 8-16, 2016.

[23] C. M. Keene, V. Y. Kong, D. L. Clarke, and P. Brysiewicz, "The effect of the quality of vital sign recording on clinical decision making in a regional acute care trauma ward,” Chinese Journal of Traumatology, vol. 20, no. 5, pp. 283-287, 2017.

[24] J. Lindo, R. Stennett, K. Stephenson-Wilson, K. A. Barrett, D. Bunnaman, P. Anderson-Johnson, V. Waugh-Brown, and Y. Wint, “An audit of nursing documentation at three public hospitals in Jamaica,” Journal of Nursing Scholarship, vol. 48, no. 5, pp. 499-507, 2016.

[25] S. A. Collins, K. Cato, D. Albers, K. Scott, P. D. Stetson, S. Bakken, and D. K. Vawdrey, "Relationship between nursing documentation and patients’ mortality,” American Journal of Critical Care, vol. 22, no. 4, pp. 306-313, 2013. 
[26] M. Flink, S. B. Glas, F. Airosa, G. Öhlén, P. Barach, H. Hansagi, M. Brommels, and M. Olsson, "Patientcentered handovers between hospital and primary health care: an assessment of medical records," International journal of medical informatics, vol. 84, no. 5, pp. 355-362, 2015.

[27] S. Austin, "Stay out of court with proper documentation," Nursing2018, vol. 41, no. 4, pp. 24-29, 2011.

[28] G. M. Keenan, E. Yakel, D. Tschannen, and M. Mandeville, "Documentation and the nurse care planning process," 2008.

[29] P. Domingues, P. Sampaio, and P. Arezes, "Beyond" audit" definition: a framework proposal for integrated management systems." 